\title{
Mediastinal Thymoma
}

National Cancer Institute

\section{Source}

National Cancer Institute. Mediastinal Thymoma. NCI Thesaurus. Code C45639.

An invasive or non-invasive thymoma that arises from the mediastinum. Thymomas are the most common anterior mediastinal tumors. 